\title{
Correction to: The Acceptance of Learning Management Systems and Video Conferencing Technologies: Lessons Learned from COVID-19
}

\author{
Mark Anthony Camilleri ${ }^{1,2}$ - Adriana Caterina Camilleri ${ }^{3}$ (D)
}

Published online: 9 September 2021

(c) Springer Nature B.V. 2021

\section{Correction to: Technology, Knowledge and Learning https://doi.org/10.1007/s10758-021-09561-y}

Following publication of the original article, the authors identified an error in Fig. 1.

The correct Fig. 1 and its caption is given in this erratum. The original article has been revised.

The original article can be found online at https://doi.org/10.1007/s10758-021-09561-y.

Mark Anthony Camilleri

mark.a.camilleri@um.edu.mt

Adriana Caterina Camilleri

adriana.camilleri@mcast.edu.mt

1 Department of Corporate Communication, Faculty of Media and Knowledge Management, University of Malta, Msida MSD2080, Malta

2 The Business School, University of Edinburgh, Bucchleuch Place, Mid-Lothian, Edinburgh EH8 9JS, Scotland, UK

3 Malta College of Arts, Science and Technology, Curriculum Department, Paola PLA9032, Malta 


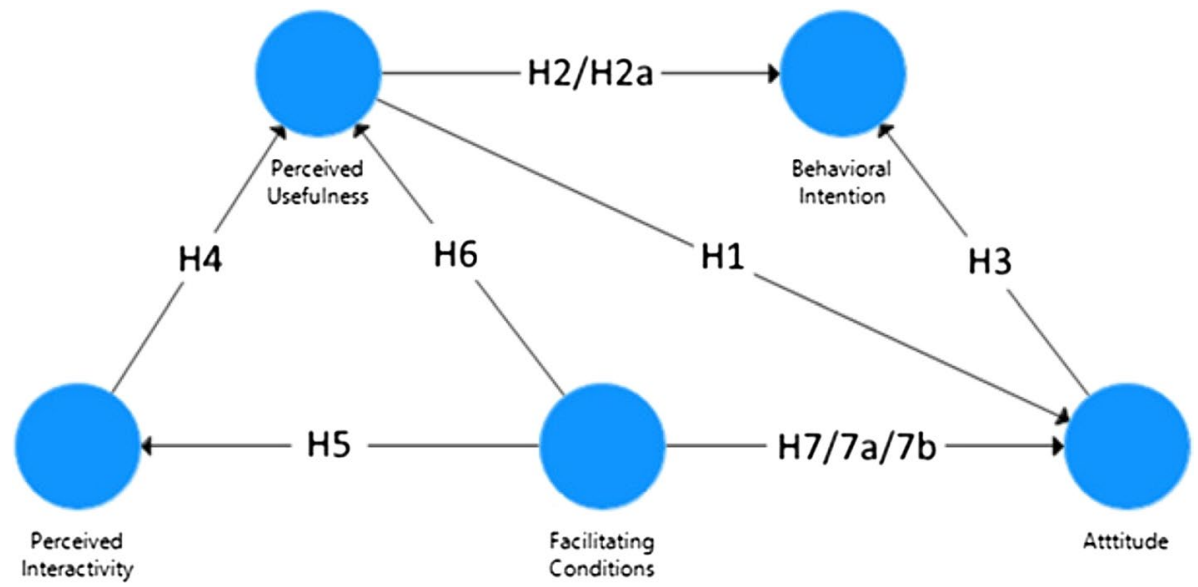

Fig. 1 A research model that investigates the individuals' intentions to use remote learning technologies

Publisher's Note Springer Nature remains neutral with regard to jurisdictional claims in published maps and institutional affiliations. 